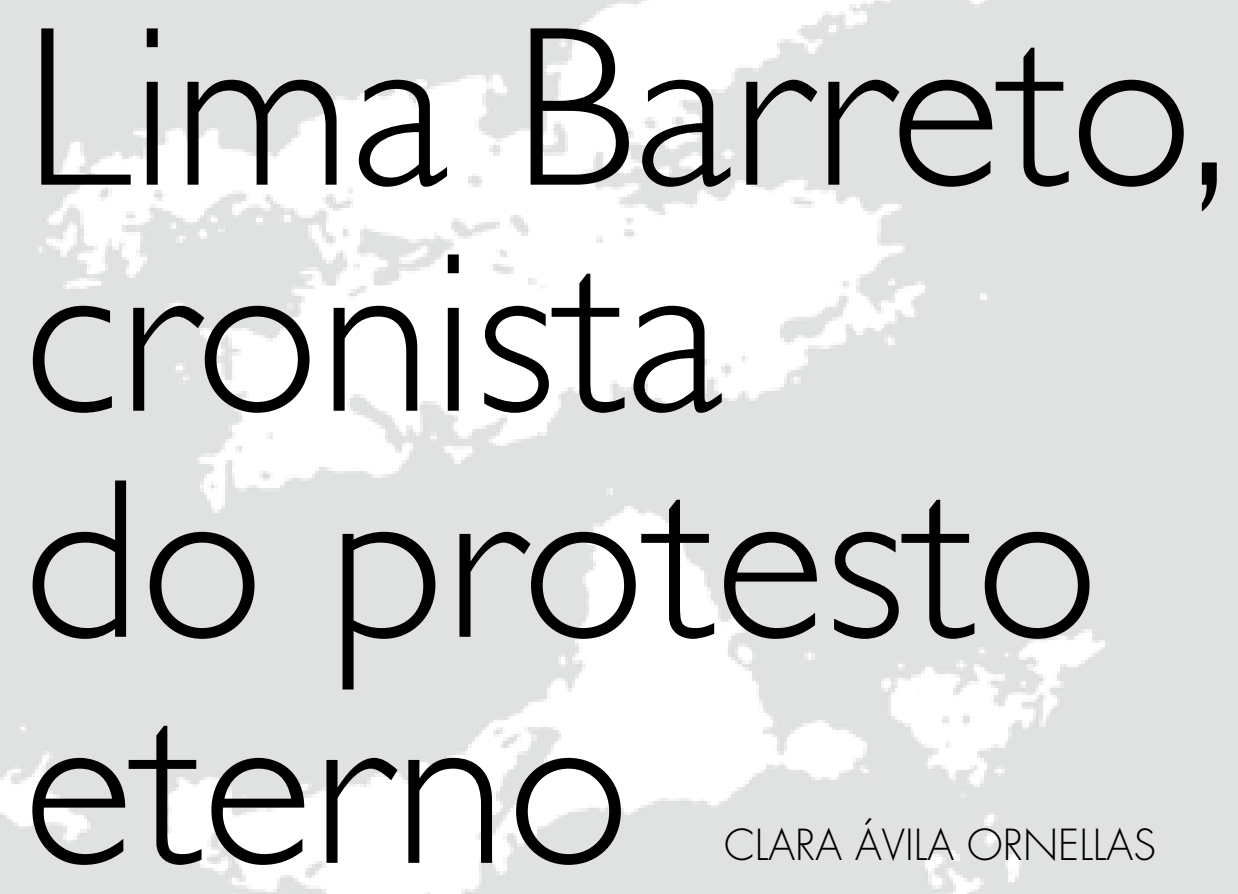

\section{CLARA ÁVILA}

ORNELLAS é doutora em Literatura Brasileira pela Faculdade de Filosofia, Letras e Ciências Humanas da USP.

\section{Toda Crônica, de} Lima Barreto, 2 vol., organização de Beatriz Resende e Rachel Valença, Rio de Janeiro, Agir, 2004, $1.248 \mathrm{pp}$.

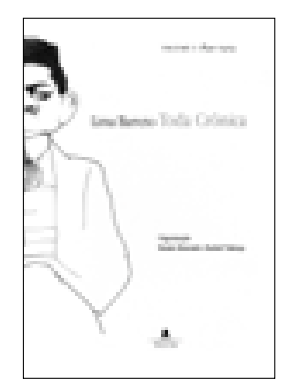

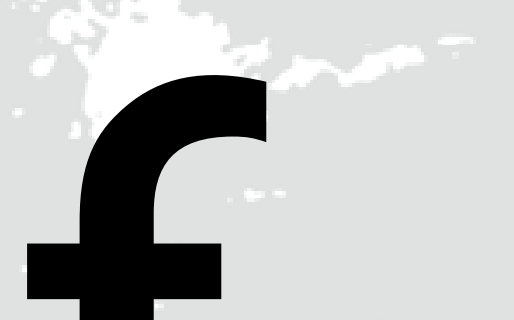

inalmente, neste início do século XXI, vêm à tona publicações que tiram doesquecimento as crônicas de Lima Barreto (1881-1922), escritor sempre negligenciado pelo mercado editorial brasileiro. A extensa produção de Lima na imprensa de sua época foi contemplada, já em 2004, na obra em dois volumes intitulada Toda Crônica (Agir), organizada por Beatriz Resende e Rachel Valença. Essa edição recupera a atividade jornalística do escritor carioca em volumes que prezam pela fidelidade aos originais, à linguagem da época, e ainda conta com três ensaios introdutórios de ótima qualidade realizados pelas organizadoras. Um dos principais fatores que chamam a atenção para a qualidade dessa publicação são os índices por nome e assunto. Esses elementos agregam valor à qualidade dessa edição porque auxiliam num maior conhecimento das áreas temáticas enfocadas por Lima, facilitando a vida dos pesquisadores e estudiosos desse escritor ou daqueles interessados ocasionalmente por sua obra. 
Trata-se de uma edição de monta que exprime uma enorme dedicação por parte das organizadoras em recuperar centenas de textos, seja nos originais pertencentes à Casa Rui Barbosa ou a José Mindlin, seja na Biblioteca Nacional em busca das primeiras publicações em jornais, revistas ou folhetins, quando não foi possível o acesso aos originais. Além disso, chama a atenção o resgate de uma fotografia inédita de Lima Barreto quando de sua internação em 1919, que revela um homem prematuramente envelhecidopeloálcool, sofrimentos domésticos e pela falta de reconhecimento literário. Chama a atenção, também, o resgate de uma crônica, até então inédita, "A Minha Alemanha".

Dessa maneira, essa edição vem complementar pertinentemente as publicações anteriores das crônicas de Lima. A primeira, mais conhecida, de 1956, pela Brasiliense organizada por Francisco de Assis Barbosa, Antônio Houaiss e M. Cavalcanti Proença, abrange toda a obra do autor em 17 volumes, sendo quatro dedicados à produção das crônicas. Cada volume conta com o prefácio de reconhecidos críticos e escritores brasileiros, como Agrippino Grieco, Astrogildo Pereira, Antônio Houaiss, Sérgio Buarque de Holanda e outros. Em 2005, temos a publicação de Lima Barreto, pela Global, vinculada à coleção Melhores Crônicas, organizada também por Beatriz Resende. Nesse volume, a organizadora seleciona crônicas de Lima pelo viés temático. Assim, torna possível conhecer alguns dos principais temas que nortearam as preocupações do escritor carioca, como o Rio de Janeiro, a sociedade, a política, a vida literária e costumes.

Por que é interessante reeditar as crônicas de Lima Barreto no início do século XXI, quase cem anos depois de suas primeiras publicações em jornais e revistas? Lima, assim como dezenas de escritores brasileiros, exerceu concomitantemente a literatura e o jornalismo em sua vida profissional. Desde sempre, era inevitável ao escritor uma segunda profissão para sobreviver. Assim foi o caso de Orestes Barbosa, Graciliano Ramos, João Antônio, Erico Verissimo, Clarice Lispector e muitos outros. Para
Lima, a situação ainda foi mais crítica pela necessidade de sustentar a família desde jovem, pois seu pai, vítima de alucinações por mais de vinte anos, só podia contar com o auxílio do filho para não terminar seus dias em uma casa de asilo público. Além de atuar como amanuense na secretaria do Ministério da Guerra - trabalho que nada tinha a ver com seus anseios de revolução social e humana-, buscou incansavelmente publicar textos em jornais para ter algum ganho extra. Acrescenta-se a isso, também, o fato de que era a única forma que tinha de se sentir atuando na vida pública, social e literária de seu tempo. Pois, segundoele, por ser negro, pobre e não ter o título de doutor, tudo lhe era negado socialmente.

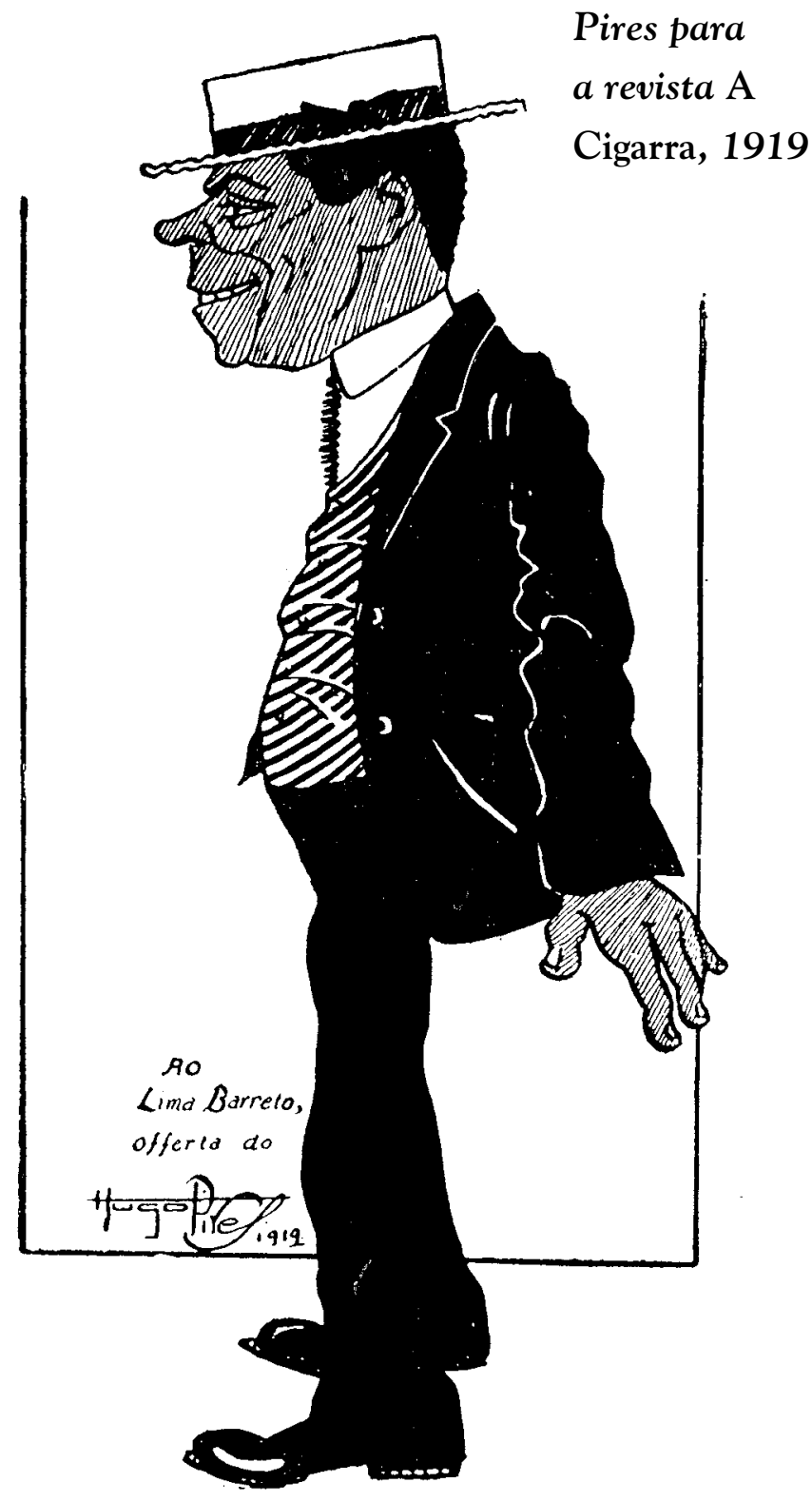

Caricatura de Lima Barreto feita por Hugo Pires para a revista $\mathrm{A}$ Cigarra, 1919 


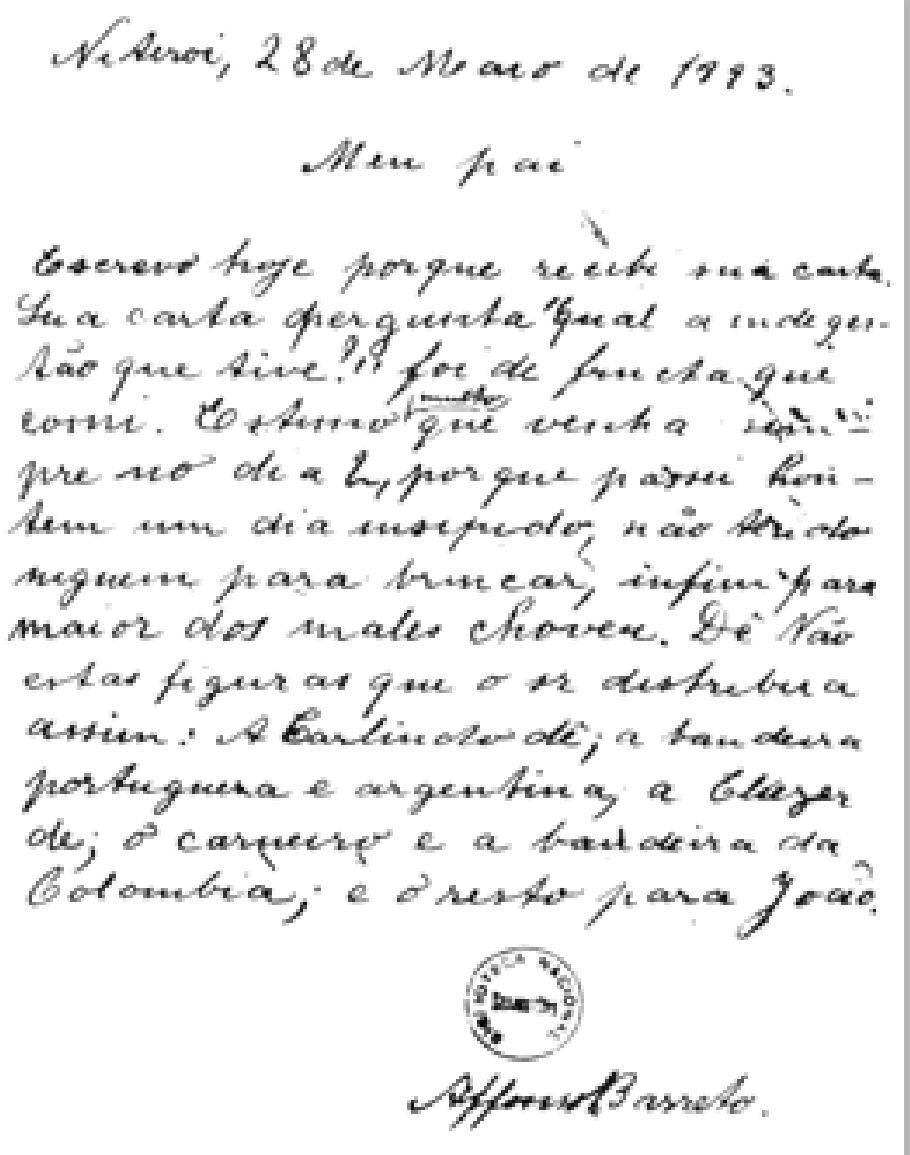

Fac-símile

de carta de

Lima Barreto

ao pai, 1893
Lima Barreto foi um incansável lutador em favor da igualdade social. Solidariedade humana é uma boa expressão para resumir seus anseios pessoais e estéticos. Para ele, a verdadeira literatura seria aquela que se prestasse a unir os homens em torno da paz. Não haveria sentido algum produzir livros somente para divulgar os costumes mesquinhos das classes abastadas. Ele teve inimigos literários e não fez questão de escondê-los: Coelho Neto, João do Rio e outros. Não à toa, chegou a dedicar algumas de suas crônicas para criticar abertamente a literatura e o homem Coelho Neto, como em "Sobre o Nosso Teatro" e "AAcademia Nacional de Medicina”. No caso de João do Rio, é singular a crônica "Carta Aberta, ao Jeito dos Bilhetes de João do Rio”.

Um dos temas abordados por Lima em suas crônicas são as freqüentes críticas ao jornalismo distante da realidade ou, muito comum, a utilização da comunicação impressa para a instauração da ideologia burguesa. Aquela imprensa que satisfazia aos ditames de quem governava o país - algo não muito diferente dos meios de informação de hoje. "Quem vive dentro do jornalismo tem a impressão de que está entre lobos; os homens de jornais se devoram" (“O Nosso Secretário”, vol. I, p. 157). Atacou os interesses escusos que permeavam as redações e, principalmente, os jornalistas e os proprietários de jornais que se vendiam por qualquer preço, não importando se para isso colocavam em dúvida a moral e os princípios éticos básicos. Não por acaso, a publicação de seu romance Recordações do Escrivão Isaías Caminha (1909), enfocando os bastidores do jornalismo da época, impediu-o de ter acesso aos grandes veículos de imprensa até o final da vida.

Lima não se intimidou, em momento algum, diante da defesa daquilo em que acreditava. Por exemplo, por ocasião das perseguições aos operários, nas então nascentes lutas por seus direitos, atacou não apenas a postura do poder ante as vergonhosas opressões contra homens humildes, bem como se posicionou contra a imprensa da época, que divulgava esses fatos configurando os operários como verdadeiros lesas-pátrias:

"Ela [a imprensa] é feita com o desconhecimento total do que se passa fora da sua roda, um pouco da política e da dos literatos, determinando esse desconhecimento um desprezo mal disfarçado pelas outras profissões, sobretudo as manuais, e pelo que pode haver de inteligência naqueles que as exercem. Junte-se a isto uma admiração estulta pelos sujeitos premiados, agaloados, condecorados, titulados e as opiniões deles; considere-se ainda as insinuações cavilosas dos espertalhões interessados nisto ou naquilo, que cercam os homens de jornais de falsos carinhos e instilam no seu espírito o que convém às suas transações..." ("Carta Aberta", vol. I, p. 426).

Sempre num posicionamento discursivo ácido e contundente, a sua militância na imprensa em prol de uma sociedade mais 
justa encontra-se registrada cabalmente. A coragem que esse escritor teve perante os meios de comunicação de sua época demonstra o esforço de um brasileiro crítico e disposto a enfrentar tudo e todos em nome de suas idéias, que muito tinham em comum com a ideologia anarquista. Em diversos textos dessa coletânea, podemos constatar várias declarações de apreço às lutas dos trabalhadores que buscavam uma sociedade justa, sem mando de governo e com homens unidos pela solidariedade. Inclusive, ele foi um dos jornalistas que em seus textos comemorou a Revolução Russa de 1917, aclamando-a como uma forma vitoriosa da luta do povo por um regime político mais justo e próximo da realidade dos marginalizados sociais.

Mereceria um estudo à parte a sua crítica ao governo. Em grande parte de suas crônicas, a contestação acirrada às incongruências do poder público está presente, seja explícita ou implicitamente. Não poupou esforços nem palavras em seus ataques. Muitas vezes permeado por ironia cáustica, ele constrói personagens alienados para configurar personalidades da vida pública. O leitor se vê de frente a prefeitos que buscaram na modernização da cidade simplesmente copiar modelos estrangeiros com vistas a inserir o Brasil na nova ordem capitalista. Que prato cheio para Lima! Aliás, diante das tresloucadas medidas dos prefeitos Pereira Passos, Paulo de Frontin, Carlos Sampaio e outros homens ligados à infra-estrutura da cidade, não seria necessária muita elaboração reflexiva para criticá-los, dado o olhar de um homem carioca que não concordava com as modificações do perímetro urbano em nome de uma nova ordem mundial que desconsiderava as reais necessidades da cidade e da população. Talvez por isso Lima Barreto tenha ido direto ao ponto: só mesmo traços de uma ambientação cômica para conquistar o melhor efeito nas críticas à nascente ideologia capitalista. Ao mesmo tempo, estabeleceu um ponto de vista ferino à realidade que o cercava, destilando sua ironia tipicamente ácida. Criatividade e uma militância incansável registram um dos raros homens no Brasil que não se intimidou por galardões e pelos anéis dos doutores.

E da mesma maneira também manteve seus ataques à República, aos ministros, industriais, governadores e deputados, enfim, a tudo o que se relacionava ao poder. "O governo é o Deus menos milagroso que há e, quando faz milagres, pesa sobremodo nas nossas algibeiras" (“A Propósito...”, vol. I, p. 148). Percebemos o quanto esse escritor/cronista não media esforços e atacava declaradamente os homens do poder com um viés irônico de que talvez sintamos falta atualmente. Em nosso tempo, apesar de termos alguns cronistas de qualidade, parece-nos que há ausência de uma postura barretiana no sentido de um engajamento constante e retilíneo. Hoje, ou se cai na crítica cômica, que mesmo atestando intensa criatividade não transcende os limites da sátira, ou então encontramos um ponto de vista crítico explícito, porém, a este falta o enfoque de humorismo. A medida eficaz entre a crítica e a ironia nos termos barretianos tornou-se rara, como raro foi Lima em sua época e, talvez, em toda a história do jornalismo brasileiro. Isso provavelmente explique a razão pela qual sua obra poreja atualidade.

Outro aspecto recorrente em sua produção é o desvelado amor pela sua cidade. À semelhança de um flâneur, Lima elaborou crônicas que revelam um amante do espaço urbano. Com um olhar atento ele registrou em seus textos as ruas, os casarões, os transportes e até a moda de seu tempo. Encontramos elementos de uma cartografia urbana detalhista adicionada a um ponto de vista criterioso dos costumes de sua época, tanto do centro quanto dos subúrbios, que, ao mesmo tempo, apontava as contradições sociais da época. Um registro incomparável do imaginário brasileiro do final do século XIX e início do século XX. Isso também se localiza em outras produções, sobremaneira, em Vida e Morte de Gonzaga de Sá (1919), obra em que a cidade configura-se como um verdadeiro personagem se autoconsumindo em eterno embate existencial entre o velho e o novo. Nesse romance, minuciosas descrições da 
ambiência geográfica e histórica do Rio de Janeiro compõem uma orquestração semelhante a uma ode às belezas da capital carioca e, ao mesmo tempo, denuncia o abandono de seu patrimônio. Do mesmo modo que o narrador nos conta a história da vida e da morte do protagonista Gonzaga de Sá, em paralelo, narra também a vida e a morte da, hoje, "cidade maravilhosa".

É principalmente a "morte" do Rio de Janeiro que Lima tematizou em suas crônicas. O homem que em menino conheceu um pouco a ambiência da monarquia não aceitou as mudanças, com bases em políticas desencontradas e incipientes, instauradas pelo regime republicano. Ao cronista não passou despercebida a posição de indiferença da sociedade diante das necessidades da nascente metrópole. "Tudo encarece e fica pela hora da morte; mas toda a nossa gente brasileira tem as vistas voltadas para as coisas do Rio, da avenida; e é preciso atendê-la quanto antes" ("Modas Femininas e Outras", vol. I, p. 16).

Mais importante que cuidar da infraestrutura do município e proporcionar melhores condições de vida aos miseráveis era saber das últimas tendências da moda e copiar o comportamento de países estrangeiros. Preservar a memória histórica, então, soava como despropósito para "as ordens do dia", estabelecidas pela sede de modernização. Pelo contrário, o apagamento do passado seria uma forma, evidentemente errônea, de instaurar-se na nova ordem mundial. Contudo, para o olhar inquiridor de Lima, isso mereceu inúmeras denúncias publicadas com veemência em suas crônicas como, por exemplo, quando da demolição do Convento da Ajuda, para a construção de um hotel. " O convento não tinha beleza alguma, mas era honesto; o tal hotel não terá também beleza alguma e será desonesto, no seu intuito de surripiar a falta de beleza com as suas proporções mastodônticas. De resto, não se pode compreender uma cidade sem esses marcos de sua vida anterior, sem esses anais de pedra que contam a sua história" (“O Convento", vol. I, p. 100). Nada mais "moderno" que isso, apagar a memória, ignorar a história.
Quem seriam os promotores desse processo de depredação? Lima nos responde:

"Fala-se, por exemplo, na vergonha que é a Favela, ali, numa das portas de entrada da cidade - o que faz a nossa edilidade? Nada mais, nada menos do que isto: gasta cinco mil contos para construir uma avenida nas areias de Copacabana. Clama-se contra as péssimas condições higiênicas do matadouro de Santa Cruz, imediatamente a prefeitura providencia chamando concorrência para a construção de um prado de corridas modelo, no Jardim Botânico, à imitação de Chantilly" ("Variações...", vol. II, pp. 484-5).

Contrariamente ao tempo de Lima, hoje, tornou-se politicamente correto a preservação dos patrimônios históricos, afinal, gera divisas e nós, brasileiros, não podemos ficar "mal na fita" da ordem global. Apela-se para o lado sentimental dos lugares antigos que são parte de nossa história, porém, muitas vezes, issoé apenas uma forma de manipulação que tem por objetivo a comercialização. Cobram-se ingressos para visitá-los e, como conseqüência, toda uma infra-estrutura é sustentada: hotéis, passagens, alimentação e assim, sucessivamente, gerando lucros para poucos.

Isso nos lembra, em grande medida, a política norte-americana, sempre em busca do capital. Aliás, um dos temas recorrentes também nas crônicas de Lima. Éinteressante notar como esse escritor, já nos primeiros anos do século $\mathrm{XX}$, antevia o perigo do culto aos Estados Unidos. Em um tempo em que nem mesmo o rádio existia, no qual só se tinha acesso à informação por meio de jornais e livros, ou seja, digamos, uma situação precária em relação aos nossos dias, Lima profetizou o perigo do processo de dominação global norte-americana que se formava.

Particularmente as crônicas "Coisas Americanas" I e II e "Ianquismo" tratam de questões extremamente atuais. Lima ataca a busca desenfreada pelolucro a qualquer preço e, ainda mais, o culto ao comportamento, costumes e a gritante falta de valorização 
da cultura brasileira por parte de seu povo, principalmente, pela elite. Lima elaborou seus textos colocando o pensamento dos Estados Unidos numa arena de luta para ser massacrado impiedosamente. Sem abrandamento aos norte-americanos e aos seus cultuadores brasileiros, trouxe à cena a voz de quem não conseguia compreender como homens, de destacada importância nacional, tanto valorizavam hábitos e costumes completamente distorcidos em relação à realidade do Brasil.

Foi o caso, por exemplo, da demolição de prédios históricos do Rio de Janeiro para a construção de arranha-céus, procedimento que julgava absurdo, pois, além de destruir a beleza da cidade, acusava o nascimento da ideologia make money brasileira, conforme expressão utilizada por ele. Lima buscou acordar ou, pelo menos, incomodar as consciências adormecidas que desmereciam qualquer valoração à ordem histórica ou sentimental quanto às nossas raízes. "Só o tempo faz o que o tempo não destrói; e seremos muito tolos se imitarmos os americanos nas suas idiotices e pretensões com o descomunal” (“O Edifício da Cruz Vermelha”, vol. I, p. 553).

Lima Barreto, morador de subúrbios cariocas, sempre na convivência com marginalizados sociais, depreendeu com muita acuidade crítica a "invasão" norteamericana no imaginário brasileiro e foi incansável nesse propósito. "Nós só vemos dos Estados Unidos o verso, não vemos o reverso ou o avesso; e este é repugnante, vil e horroroso" (“O Nosso "Ianquismo"”, vol. I, p. 480).

Com sua crítica sempre contundente, apontou as ações dos americanos em busca, primordialmente, do acúmulo de capital. A vida humana não era imprescindível, o ser humano só teria importância se fosse consumidor. Se houvesse o lançamento de um novo medicamento para uma doença não muito comum, segundo Lima, era bem capaz de os americanos envenenarem a água para que um grande contingente adoecesse e, assim, a venda estupenda do referido medicamento estaria garantida. Da mesma maneira, ele alertou para o nascimento da indústria da guerra, outra característica que o revela simpatizante do movimento anarquista. As lutas entre países seriam um modo de sustentar os empresários armamentistas e tomar a riqueza de outros países não importando, evidentemente, o número de mortos, mas sim o lucro que adviria dessa empreitada. E, nesse aspecto, a posição dos Estados Unidos era muito clara, afinal, foi a partir da Primeira Guerra Mundial que ele começou a tornar-se potência mundial.

$\mathrm{Na}$ contramão desse congraçamento à cultura norte-americana, tem Lima Barreto uma posição muito clara no jornalismo e na literatura brasileira. Isso se explicaria pelo seu incansável registro da realidade dos subúrbios cariocas, pela valorização dos costumes, do imaginário e da linguagem popular. Enquanto a elite buscava amealhar e importar o comportamento e o pensamento dos norte-americanos ou europeus, Lima em suas publicações na imprensa em veículos de pouca repercussão ou dos movimentos operários, resgatava a cultura do povo brasileiro. É notável a constante presença de expressões populares em suas crônicas. Muitas vezes utilizadas para enfatizar a ironia à sociedade, ele encarnou as falas das ruas e, assim, tornou seus textos prenhes de humorismo e provocação: “Cá e lá, más fadas há...” (“A Superstição do Doutor”); “Cada macaco no seu galho" ("A Superstição do Doutor")"; "Ri-se o roto, lá diz o povo, do esfarrapado e o torto do aleijado" (“A Nossa Situação"); "Atirar no que viu e matar o que não viu” ("Pobre Euclides!”); “Diz o povo que quem é pobre, peça a Deus que o mate e ao diabo que o carregue" ("Extravagâncias Oficiais"). Dessa maneira, percebe-se o quanto a escrita desse escritor/cronista nos oferece um leque de registros que auxiliam no conhecimento do pensamento e do comportamento das camadas marginalizadas do final do século XIX e início do século XX. Um verdadeiro filet mignon para os lingüistas e estudiosos dos costumes brasileiros.

Um dos diferenciais das crônicas de Lima é que mesmo sendo inteiramente a favor dos marginalizados sociais não deixou de criticar certos limites do pensa- 
"O povo até agora tem esperado por leis repressivas de tão escandaloso estanco [a carestia dos alimentos básicos], que é presidido por um ministro de Estado. Elas não virão, fique certo; mas há ainda um remédio: é a violência. Só com a violência os oprimidos têm podido se libertar de uma minoria opressora, ávida e cínica; e, ainda, infelizmente, não se fechou o ciclo das violências" ("Sobre a Carestia”, vol. I, p. 286).

Um dos pontos recorrentemente abordados em suas crônicas foi a questão da adoração e respeito que a sociedade em geral devotava àqueles que portavam o título de doutor. Percebe-se que muitos de seus textos sobre esse tema estão relacionados a um ponto de vista polemizador ante o ensino, às maneiras como muitos faziam para obter o diploma e mesmo ao fato de se tirar profissionais capacitados, mas sem formação canônica, do serviço público para que os cargos fossem ocupados pelos "doutores". Entretanto, encontramos também a percepção de que um dos responsáveis por essa situação era o próprio povo, por sustentar a visão de que os doutores eram seres superiores a quem deviam respeito e dedicação.

Nessa mesma linha de crítica aos costumes, observamos em suas crônicas um extenso leque de críticas ao comportamento suburbano que, na grande maioria, repetia a hierarquia da elite entre si. É o caso dos pequenos funcionários públicos que nos trens portavam-se como seres melhores que os demais trabalhadores, apenas porque trabalhavam neste ou naquele órgão do governo, ainda que fosse como simples office-boys ou escrivães. "Todo brasileiro nasceu mais ou menos para ser um tiranozinho em qualquer coisa, [...] trata logo de pôr pessoalmente em ação a autoridade de que está investido pelo Estado místico” (“O Encerramento do Congresso”, vol. II, p. 487).

Observamos também esse cronista da sociedade criticando as mulheres pobres que buscavam se vestir conforme a moda da Rua do Ouvidor, ainda que para isso tivessem que sacrificar as necessidades domésticas. Também entre os moradores da periferia, Lima localizou o preconceito racial em que os brancos, mesmo pobres e sem instrução, se sentiam portadores de uma "graça divina", que lhes alçava a um patamar de superioridade entre os habitantes de sua comunidade. Essa temática também compõe o romance Clara dos Anjos (1922), que, além disso, aborda outras questões da incoerência do comportamento suburbano. O tema do racismo em todas as esferas sociais, inclusive, foi uma das principais lutas que Lima empreendeu em toda a sua produção jornalística e literária.

Lima Barreto, conforme atestamos, defendeu ardentemente tudo em que acreditava e a crônica foi um espaço importante para a divulgação de seu pensamento. Mesmo que hoje nos pareça absurdo, ele assim também atacou, em vários textos, as mulheres e o futebol. Não concordava com a presença de mulheres no serviço público e nem com a possibilidade do voto feminino. Ao mesmo tempo, porém, defendeu ardentemente o direito da mulher de amar quem quisesse, polemizando com o direito dos maridos de matar "em legítima defesa", em caso de adultério. $\mathrm{O}$ futebol mereceu diversos textos e era criticado principalmente pordiscriminar o negro, o pobre, causar doenças, incitar à violência e, principalmente, por ser uma cultura importada. Se concordamos ou não com essas opiniões, isso não vem ao caso, e sim o fato de localizarmos aqui um homem que não abandonou seus ideais até a morte.

Ressaltamos que muitos outros temas foram abordados por Lima Barreto em suas crônicas. Contudo, acreditamos ter realizado uma abordagem geral que nos mostra o quanto é importante recuperarmos a escrita desse escritor carioca, diante da qual as críticas literária e jornalística ainda estão em dívida. Um homem que se manteve fiel aos seus princípios e não se calou diante de fatos que contradiziam seus ideais de uma sociedade justa e pacífica. Limanão se intimidou perante a sua situação de marginalizado literário, racial e social e configura-se como um exemplo atemporal de luta em favor da igualdade de direitos. "Eu não me canso nunca de protestar. Minha vida há de ser um protesto eterno contra todas as injustiças" ("Padres e Frades", vol. I, p. 326). 